\title{
Exploring vector space: overcoming resistance to direct control of the tobacco industry
}

\author{
Cynthia Callard, Neil E Collishaw
}

Physicians for a Smoke-Free Canada, Ottawa, Ontario, Canada

\section{Correspondence to} Cynthia Callard, Physicians for a Smoke-Free Canada, 1226 A Wellington Street, Ottawa, Ontario, Canada K1Y 3A1: ccallard@smoke-free.ca

Received 11 April 2011 Accepted 22 August 2011
Within the epidemiological framework that describes the relationship of smokers (host), cigarettes (agent), tobacco companies (vector) and environment, ${ }^{1}$ both the agent and the vector are man-made and, in theory, controllable. Nonetheless, the smoking pandemic is expected to claim one billion lives in this century, even among people who are not yet born. ${ }^{2}$ With a preventable problem that is not being prevented, our disease strategy is arguably in need of a rethink.

While health science has focused on establishing the link between tobacco products and the diseases they cause, treating those diseases, exploring ways to make cigarettes less harmful and ways to discourage tobacco use, relatively little health research has been focused on analysing the vector of the disease or how to change its course. ${ }^{3}$ This may explain why there is a global consensus to modify the behaviour of the host, environment and agent, but little pressure in support of vector control. ${ }^{4}$

Despite opposition to such supply-side approaches, ${ }^{2} 5$ a number of new vector-related tobacco control measures have been proposed. These include performance-based regulations, ${ }^{6}$ ending the manufacturer's obligation to increase or at least maintain shareholder value, ${ }^{7}$ regulating profits, ${ }^{8}$ banning some or all tobacco products or prohibiting use by some people, ${ }^{9-11}$ imposing targeted reductions on supply, ${ }^{12}{ }^{13}$ penalising manufacturers for youth smoking, ${ }^{14}$ forcing tobacco companies to internalise the costs of smoking through fees or liability, ${ }^{15}$ resisting the privatisation of state-owned tobacco companies ${ }^{16}$ and other strategies. ${ }^{17}$

None of these have yet been adopted into policy, except in Bhutan. ${ }^{18}$ A New Zealand legislative committee recently proposed 'annually reducing (by a set percentage) the amount of imported tobacco, the number and quantity of tobacco products for sale at each outlet, and the number of retail outlets, ${ }^{19}$ but the official government response leaves open whether or how this might be accomplished. ${ }^{20}$

Exploratory research into resistance to supplyside tobacco control interventions suggests that existing mindsets may hinder the adoption of these measures, including the 'ingrained, widespread and pervasive' acceptance of free market thinking and a preference for change to be evolutionary or incremental. ${ }^{21}$ These mindsets may result from gaps in knowledge and experience that can be filled through specific actions by vector control proponents.

\section{ESTABLISHING THE BUSINESS CASE FOR VECTOR} CONTROL

We are not aware of any investment research designed to support public investments in vector control. By contrast, private capital markets have access to significant investment research, including a recent analysis that cautioned investors against the likely reduction in tobacco industry shares that might arise as a result of tobacco control successes. $^{22}$ This illustrates the pressures that tobacco industry managers with responsibilities to shareholder value are under to overcome these measures and to keep smoking rates high, ${ }^{7}$ as well as the inverse relationship between the economy of the vector and progress against smoking.

Available data suggest, at least at a prima facie level, that the business case for vector control may be very solid.

On the cost side of the equation, we know that the value of the privately owned global tobacco industry is about US $\$ 450$ billion. ${ }^{23}$ (Despite the reported pervasiveness of free market thinking cited above, about $40 \%$ of the cigarettes sold worldwide are manufactured by state-owned tobacco companies. $)^{16}$

On the benefit side of the equation, we know that former World Bank economist Howard Barnum calculated that tobacco use resulted in a global annual loss of US $\$ 200$ billion for 1990, or almost $1 \%$ of the global GDP. ${ }^{24}{ }^{25}$ A comparable percentage of the 2009 global GDP would be an annual cost of US\$530 billion, more than the market capitalisation of the private companies. A recent study for the Canadian government reported that the present value of one typical smoker quitting in mid-life was \$C 421000 (or $900 \%$ of percapita GDP). ${ }^{26} 27$ At this value, achieving one million fewer smokers would provide a value equal to the market value of the privately-owned companies.

\section{DISABLING THE PUMP}

Another barrier that may need to be overcome before vector control is accepted is the reluctance by public health authorities to innovate in the face of uncertainty and against prevailing attitudes. Yet, a famous episode from public health history speaks of the benefits of governments taking a leap of faith in advance of scientific consensus.

Today's demand-reduction approach to tobacco control has aspects in common with cholera control in the mid-19th century. Like us, the Victorian-era sanitarians relied on measures that focused on the host and environment, such as the removal of environmental contaminants (ie, dead meat/tobacco advertisements) and the promotion of healthier lifestyles (ie, washing/not smoking). They backed away from approaches (ie, quarantines/import bans) that challenged commercial and trade interests. They had significant scientific 


\section{What this paper adds}

Applying the framework of host-agent-vector-environment to tobacco control research reveals that public health interventions that focus on the vector (tobacco industry) are less studied, less applied and less accepted than policies that focus on the smoker (host), the environment or the tobacco product (agent). This may explain why proposals to impose different styles of direct control on the tobacco industry have not been implemented.

- Proponents of supply-side tobacco control could demonstrate that the economic value of directly controlling the industry greatly exceeds the cost of doing so, and that there is no need to wait for a scientific consensus before actively recruiting a government to innovate in this area.

evidence to support their approach and a consensus against competing theories. ${ }^{28}$

Yet, John Snow is celebrated today because he convinced local authorities to transcend this mindset and to remove the pump handle from a well he suspected was the source of cholera. (Snow won a place in history, but gained few allies among his contemporaries. It would be decades after his death before his pinpointing the Broad Street pump as the source of cholera transmission was seen as a pioneering act of vector control for infectious disease.) Less celebrated is the Parish Council that, in the face of an opposing scientific consensus, was willing to act on Snow's advice and disable the pump.

The adoption of vector control in the tobacco industry may similarly require a pioneering spirit and willingness by governments to innovate against an established consensus.

Tobacco control strategies focused on host, agent and environment have slowed but have not stopped the tobacco pandemic from its relentless spread. Finding a government willing to experiment with 'disabling the pump' may establish vector control as a key part of the 'end game' for tobacco.

\section{Competing interests None.}

Contributors Both authors contributed to the development of the ideas. CC wrote the paper.

Provenance and peer review Not commissioned; externally peer reviewed.

\section{REFERENCES}

1. Davis RM, Smith R. Addressing the most important preventable cause of death. A new journal on tobacco control. BMJ 1991;303:732-3.

2. Jha P, Chaloupka FJ, Moore J, et al. Tobacco addiction. In: Jamison DT, Breman JG, Measham AR, et al, eds. Disease Control Priorities in Developing Countries. 2nd edn. Washington, DC: Oxford University Press and the World Bank, 2006.
3. Cohen JE, Chaiton MO, Planinac LC. Taking stock. A bibliometric analysis of the focus of tobacco research from the 1980s to the 2000s. Am J Prev Med 2010;39:352-6.

4. World Health Organization. Framework Convention on Tobacco Control. World Health Assembly Resolution 56. 1, 21 May 2003.

5. Liberman J. The future of tobacco regulation: a response to a proposal for fundamental institutional change. Tob Control 2006;15:333-8.

6. Sugarman SD. Performance-based regulation: enterprise responsibility for reducing death, injury and disease caused by consumer products. J Health Polit Policy Law 2009;34:1035-77.

7. Callard C, Thompson D, Collishaw N. Transforming the tobacco market: why the supply of cigarettes should be transferred from for-profit corporations to non-profit enterprises with a public health mandate. Tob Control 2005;14:278-83.

8. Gilmore AB, Branston JR, Sweanor D. The case for OFSMOKE: how tobacco price regulation is needed to promote the health of markets, government revenue and the public. Tob Control 2010;19:423-30.

9. Hall W, West R. Thinking about the unthinkable: a de facto prohibition on smoked tobacco products. Addiction 2008;103:873-4.

10. Tobacco Strategy Advisory Group. Building On Our Gains, Taking Action Now: Ontario's Tobacco Control Strategy For 2011-2016. Toronto, Canada: Ontario Ministry of Health Promotion and Sport, 2010.

11. Khoo D, Koong HN, Berrick AJ, et al. Phasing-out tobacco: proposal to deny access to tobacco for those born from 2000. Tob Control 2010;19:355-60.

12. Enzi M. Help End Addiction to Lethal Tobacco Habits Act. S. 1834. US Senate, 2007

13. Thomson G, Wilson N, Blakely T, et al. Ending appreciable tobacco use in a nation: using a sinking lid on supply. Tob Control 2010;19:431-5.

14. Glantz SA. Removing the incentive to sell kids tobacco. A proposal. JAMA 1993:269:793-4

15. Tiesse J, Hunt $P$, Celia $C$, et al. Assessing the impacts of revising the tobacco products directive. Study to support a DG Sanco impact assessment. Santa Monica CA: RAND Corporation, 2011.

16. Gilmore $\mathbf{A B}$, Fooks G, McKee M. A review of the impacts of tobacco industry privatization: implications for policy. Glob Public Health 2011;6:621-42.

17. Malone RE. Imagining things otherwise: new endgame ideas for tobacco control. Tob Control 2010;19:349-50.

18. Ugen S. Bhutan: the world's most advanced tobacco control nation? Tob Control 2003;12:431-3.

19. Maori Affairs Committee of New Zealand Parliament. Inquiry into Tobacco Industry in Aotearoa. Report of the Maori Affairs Committee. Wellington: New Zealand Government, 2010.

20. Government of New Zealand. Government Final Response to Report of the Māor Affairs Committee on Inquiry into the tobacco industry in Aotearoa and the consequences of tobacco use for Māori, presented to the House of Representatives in accordance with Standing Order 248 (J.1). Wellington: New Zealand Government, 2011.

21. Edwards E, Russell M, Thomson G, et al. Daring to dream: reactions to tobacco endgame ideas among policy makers, media and public health practitioners. BMC Public Health 2011;11:580

22. Spielman A. Tobacco: what if the last smoker quits in 2050? New York: Citigroup Global Markets, 2011.

23. Alacrastore. Tobacco Industry Snapshot. http://www.alacrastore.com/companyindex/public/Tobacco-89 (accessed 28 Mar 2011).

24. Barnum H. The economic burden of the global trade in tobacco. Tob Control 1994;3:358-61.

25. World Bank. World Data Bank. http://databank.worldbank.org/ddp/home.do (accessed 28 Mar 2011).

26. Health Canada. Tobacco products labelling regulations (cigarettes and little cigars). Regulatory impact analysis statement. Ottawa: Canada Gazette Part I, 145 No. 8.

27. Statistics Canada. Population by year, Ottawa: CANSIM Table 050-001, 2007.

28. Smith GD. Commentary: behind the broad street pump: aetiology, epidemiology and prevention of cholera in mid-19th century Britain. Int $J$ Epidemiol 2002;31:920-32. 